\title{
Panel cutting method: new approach to generate panels on a hull in Rankine source potential approximation
}

\author{
Hee-Jong Choi ${ }^{1}$, Ho-Hwan Chun ${ }^{2}$, Il-Ryong Park ${ }^{3}$ and Jin Kim ${ }^{4}$ \\ ${ }^{I}$ Dept. of Naval Architecture \& Ocean Engineering, Chonnam National University, Yeosu, Korea \\ ${ }^{2}$ Dept. of Naval Architecture \& Ocean Engineering, Pusan National University, Busan, Korea \\ ${ }^{3}$ Dept. of Naval Architecture \& Ocean Engineering, Dongeui University, Busan, Korea \\ ${ }^{4}$ Maritime and Ocean Engineering Research Institute, KORDI, Daejeon, Korea
}

\begin{abstract}
In the present study, a new hull panel generation algorithm, namely panel cutting method, was developed to predict flow phenomena around a ship using the Rankine source potential based panel method, where the iterative method was used to satisfy the nonlinear free surface condition and the trim and sinkage of the ship was taken into account. Numerical computations were performed to investigate the validity of the proposed hull panel generation algorithm for Series 60 $\left(C_{B}=0.60\right)$ hull and KRISO container ship (KCS), a container ship designed by Maritime and Ocean Engineering Research Institute (MOERI). The computational results were validated by comparing with the existing experimental data.
\end{abstract}

KEY WORDS: Hull panel generation; Rankine source potential based panel method; Nonlinear free surface condition; Iterative method; Series $60\left(\mathrm{C}_{\mathrm{B}}=0.60\right)$ Hull; KRISO Container ship (KCS).

\section{INTRODUCTION}

Minimization of the resistance of a ship is an important issue in ship design. The resistance is determined by hydrodynamic forces, which strongly depend on the shape of the hull. Resistance consists mainly of a viscous resistance associated with the generation of a boundary layer and a wave-making resistance connected with the excitation of a wave pattern.

For most commercial ships the viscous resistance component is dominant, while the wave resistance in practical cases amounts to 10 to $60 \%$ of the total resistance, depending on the operating speed. The wave resistance is virtually zero at relatively low speeds and increases very quickly at higher speeds. The wave resistance is very sensitive on the shape of the hull and is easily influenced by relatively small design modifications, which means that wave resistance plays an important role in hull form design.

In general, the total resistance was measured at a towing tank with a scaled model. At the same Froude number, a model test produces a wave pattern geometrically similar to that of a ship and the wave resistance of the ship is theoretically predicted by that of the model. Optimizing the shape of the hull to reduce the wave resistance is a difficult task which requires both the practical experience and

Corresponding author: Ho-Hwan Chun

e-mail: chunahh@pusan.ac.kr intuition of naval architects, while the empirical approach has been complemented by numerical analysis.

The Rankine source panel method has been found to give fairly realistic results in general, and to be quite efficient and flexible, where the nonlinear free surface condition was linearized such as for the well known Kelvin free surface condition and satisfied in an iterative manner. The Rankine source panel method has been used in many practical ship design. The use of this method caused a significant change in the hull form design procedure (Baba and Takekuma, 1975; Brandsma and Hermans, 1985; Dawson, 1977; Eggers, 1981; Gadd, 1976; Newman, 1976; Raven, 1996).

In the Rankine source panel method the quality of the panels surrounding the boundaries is very important in order to obtain reliable results. In general, computational grid for flow calculation requires some characteristics such as orthogonality, smoothness, adequate concentration, configuration like streamlines and so on. Jensen (1990) developed an efficient interface program, linking computer aided ship hull form design and the evaluation of seakeeping and wave resistance performance. The interface program took the curves from the ship hull form database, and made a panel model of the ship hull form with only minor input from the operator. The panel model was the geometric input for the calculation of seakeeping and wave resistance characteristics. Kouh and Chau (1993) generated the grid for hull forms using rational cubic Bezier curves. In the paper a hull form was defined by two sets of grid lines-transverse grid lines 
arranged in length direction and longitudinal grid lines arranged in depth direction. Transverse lines were first defined, the points on the transverse lines with the same curve parameter values were then fitted to define longitudinal lines. Kim and Van (1999) developed a hull surface mesh generation program, based on given station offsets and centerline profile which employed non-uniform parametric splines and generated hull surface meshes can be utilized for the Rankine source panel method immediately. Bronsart et al. (2004) proposed the automatic panel generation method of a ship hull surface for wave resistance calculation. In the paper two algorithms were presented with the objective to facilitate the fully automatic panel mesh generation and the stability of the algorithm and the applicability to all ship forms and the regularity of the panel mesh as required for CFD calculations were taken in account. Ko et al. (2011) developed the panel generation system for analyzing seakeeping performance of a ship. The system was designed to handle various kinds of ships such as ships with a mono-skeg, a twin-skeg and/or a bulbous bow in either an automatic or an interactive manner.

In the iterative method, to satisfy the nonlinear free surface condition, the panels on the hull should be changed according to the wave profile in the immediate vicinity of the ship found in the previous iteration and the generation of hull panels should be carried out automatically using the initially given hull geometry information in every iteration. It is not easy to maintain an initially given hull geometry if the ship has an intricate design or if the ship experiences excessive dynamic trim and sinkage. Therefore, the generation of the hull panels could be a particularly serious problem to tackle. In particular, there has been controversy on the panel generation for a ship with a goose-neck bulb which emerges over the free surface in severe trim or ballast condition. To solve this problem in a practical way, an additional sinkage is applied to the ship which means that the ship is enforced to be fully submerged. In this case, the numerical results are dependent on the additional sinkage condition. Therefore, a new analysis technique without the additional sinkage needs to be developed.

In the present study, a new hull panel generation technique was proposed in which the panel on the hull was re-generated, making the best use of the initially given panels. The Rankine source panel method was used with the fully nonlinear free surface condition, which was satisfied by the iterative method and the dynamic trim and sinkage were taken into account. Numerical computations were performed to investigate the validity of the proposed algorithm using Series $60\left(C_{B}=0.60\right)$ hull and KRISO container ship (KCS) designed by Maritime and Ocean Engineering Research Institute (MOERI). The computational results were validated by comparing them with the existing experimental data.

\section{POTENTIAL FLOW METHOD}

The coordinate system moves with the ship at the same longitudinal speed but does not follow its dynamic trim and sinkage and the origin is chosen at the centerplane of the ship at the midship section, at the level of the undisturbed waterplane. The $\mathrm{x}$-axis is horizontal and points astern, the $\mathrm{y}$ axis is positive to starboard, and the z-axis is upward as shown in Fig. 1.
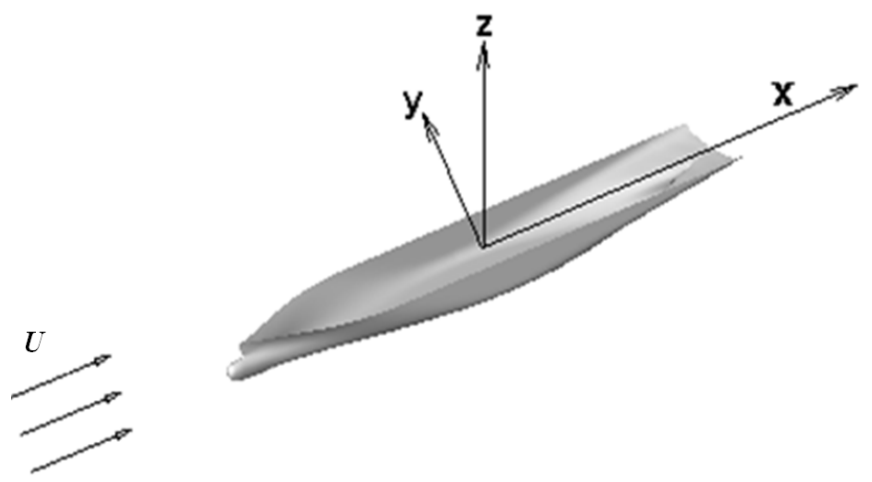

Fig. 1 Coordinate system.

In the unawareness of the viscosity of the fluid and wave breaking, the irrotationality of the incoming flow is preserved and a potential flow may be assumed in which the velocity vector is defined as the gradient of a velocity potential, $\phi$. The velocity potential is governed by the Laplace equation as the fluid is assumed to be incompressible.

$\nabla^{2} \phi=0$ in the fluid region

Over the wetted part of the hull surface, the fluid particle should not penetrate the hull surface and the normal component of the flow velocity on the hull surface should be zero.

$\phi_{n}=0$ on the hull surface

where $_{n}$ is the unit normal vector.

On the free surface, the flow velocity must be tangential to the free surface, which means that the flow particle at the free surface should not leave the free surface.

$\phi_{x} h_{x}+\phi_{y} h_{y}-\phi_{z}=0$ on the free surface

where $h$ is the wave elevation.

The pressure on the free surface, which is expressed in the flow velocities and wave elevation through Bernoulli's law, should be constant at the free surface.

$g h+\frac{1}{2}\left(\phi_{x}^{2}+\phi_{y}^{2}+\phi_{z}^{2}-U^{2}\right)=0$ on the free surface

where $U$ is the speed of the ship.

Since equations (3) and (4) are fully nonlinear equations, in this paper the iterative method was used to solve the free surface problem based on the Rankine source panel method.

The disturbance due to the ship approaches zero and the velocity potential should be the same as the incoming velocity potential, as the distance from the ship approaches infinity. 
$\nabla \phi=(U, 0,0)$ as $x \rightarrow-\infty$

Having obtained the velocity potential and hence the flow velocity, the pressure coefficient, $C_{p}$ at each panel can be found using Bernoulli's equation.

$C_{p}=1-\frac{\nabla \phi \bullet \nabla \phi}{U^{2}}-2 \frac{z}{F n^{2}}$

where $F n$ is the Froude number.

The wave-resistance coefficient, $C_{W}$ is hence given by integration of the pressure coefficient over the wetted hull surface

$C_{W}=-\frac{\int_{S} C_{p} n_{x} d s}{S}$

where $S$ is the wetted surface of the hull.

\section{PANEL CUTTING METHOD}

In this method, hull panels are generatd using only the initially given hull panels on the assumption that the initially given hull panels are of the best quality. Attempts are made to keep the modification of the initially given panels to a minimum and to make the best use of the initially given hull panels.

\section{Algorithm of panel cutting method}

Fig. 2 shows the panel and the free surface which passes across the panel. The geometrical points representing the panel and the free surface are projected onto the $x z$-plane as shown in Fig. 2. After the intersection points where $L_{1}=L_{2}$ and $L_{1}=L_{3}$ are calculated, the panel to be used in the next iteration is generated simply connecting the intersection points and the vertices of the original panel below the free surface.

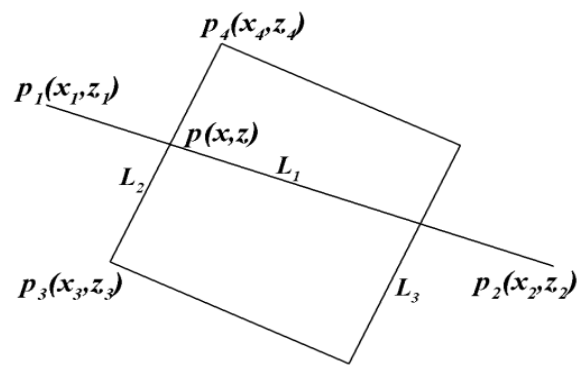

Fig. 2 Geometrical definition of the panel and the free surface

In Fig. 2 the equations of the lines $\left(L_{1}\right.$ and $\left.L_{2}\right)$ are defined as follows.

$L_{1}=p_{1}+u_{1}\left(p_{2}-p_{1}\right)$
$L_{2}=p_{3}+u_{2}\left(p_{4}-p_{3}\right)$

Solving for the point where $L_{1}=L_{2}$ gives the following two equations in two unknowns $\left(u_{l}\right.$ and $\left.u_{2}\right)$.

$x_{1}+u_{1}\left(x_{2}-x_{1}\right)=x_{3}+u_{2}\left(x_{4}-x_{3}\right)$

$z_{1}+u_{1}\left(z_{2}-z_{1}\right)=z_{3}+u_{2}\left(z_{4}-z_{3}\right)$

Solving gives the following expressions for $u_{1}$ and $u_{2}$.

$u_{1}=\frac{\left(x_{4}-x_{3}\right)\left(z_{1}-z_{3}\right)-\left(z_{4}-z_{3}\right)\left(x_{1}-x_{3}\right)}{\left(z_{4}-z_{3}\right)\left(x_{2}-x_{1}\right)-\left(x_{4}-x_{3}\right)\left(z_{2}-z_{1}\right)}$

$u_{2}=\frac{\left(x_{2}-x_{1}\right)\left(z_{1}-z_{3}\right)-\left(z_{2}-z_{1}\right)\left(x_{1}-x_{3}\right)}{\left(z_{4}-z_{3}\right)\left(x_{2}-x_{1}\right)-\left(x_{4}-x_{3}\right)\left(z_{2}-z_{1}\right)}$

Substituting either of these into the corresponding equation for the line gives the intersection point $p(x, y)$.

$x=x_{1}+u_{1}\left(x_{2}-x_{1}\right)$

$z=z_{1}+u_{1}\left(z_{2}-z_{1}\right)$

\section{Cases of panel cutting method}

To generate the hull panels, the positional relationship between a free surface and the 4 vertices of a panel should first be checked and if the panel is below the free surface it is included in the numerical computation, while if the panel is above the free surface the panel is not included. As a special case, the free surface intersects the panel and the panel is then re-generated only for the part of the panel submerged below the free surface.

In Figs. 3 and 4, the panels described with the solid line are newly generated and are included in the numerical computation, while the panels with the dotted line are not included. The numbers outside the panel written in Gothic type are given as an input sequence for the initially given panels, while the numbers inside the panel written in Italic type are given as an input sequence for the newly generated panels.

Fig. 3-1 shows the panel and the free surface in which all 4 vertices of the panel are below the free surface and the panel is included in the numerical computation; however, in Fig. 3-2, the panel is not included because it is above the free surface.

In the hull panel generation process using the panel cutting method, an intersection between the panel and the free surface could occur and there are 6 possible intersection cases as shown in Fig. 4. In Fig. 4-1, the panel is divided into 2 quadrilateral panels in which, as mentioned above, only the panel below the free surface is included in the numerical computation, while in Fig. 4-2, the triangular panel is generated below the free surface. In Figs. 4-3 and 4-4, the 4th vertex is on the free surface and the quadrilateral panel and the triangular panel are generated, respectively. In Figs. 4-5, 
the 2nd and 4th vertices are on the free surface and the triangular panel is generated. In Fig. 4-6, the panel is divided into the pentagonal panel and the triangular panel by the free surface and the pentagonal panel is divided into the 2 quadrilateral panels.
$\underline{F S}$

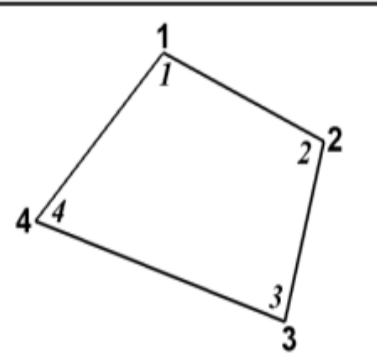

$(3-1)$

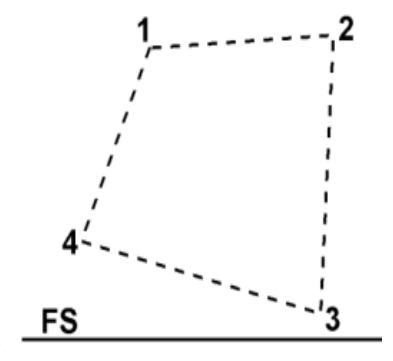

$(3-2)$
Fig. 3 Panels below and above the free surface

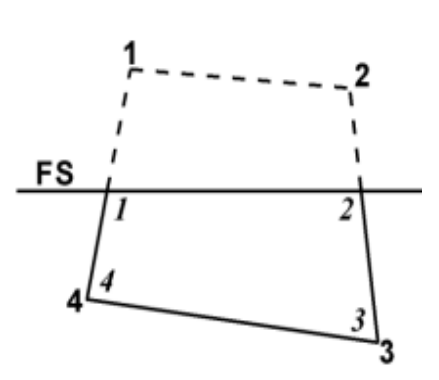

$(4-1)$

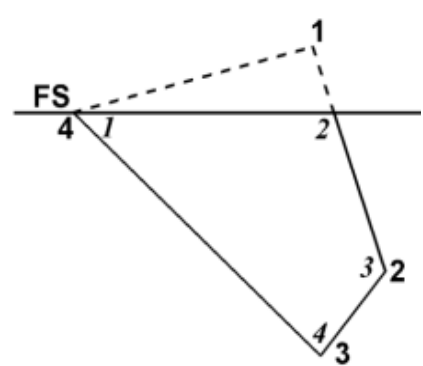

(4-3)

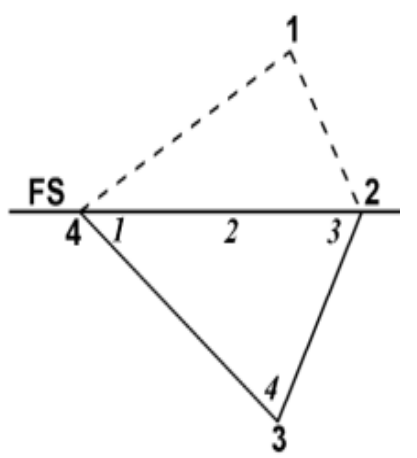

(4-5)

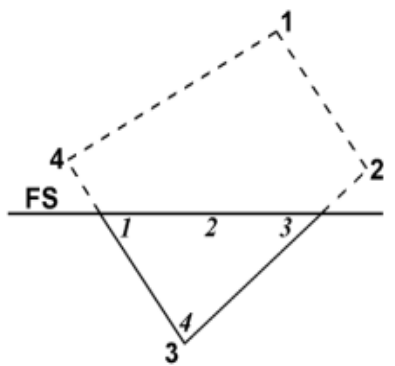

$(4-2)$

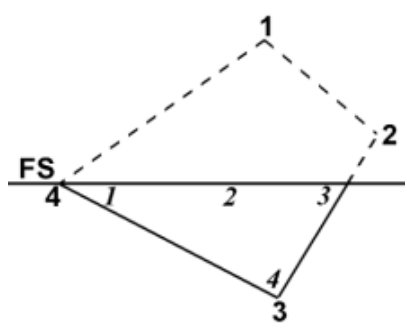

(4-4)

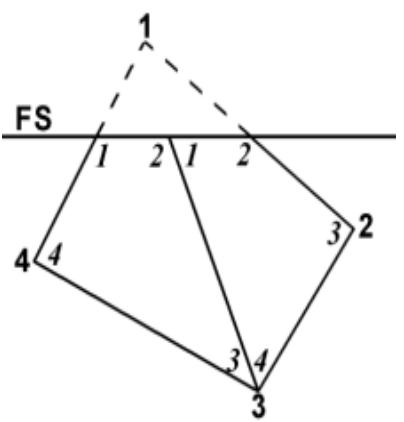

(4-6)
Fig. 4 Cases of the intersection between the panel and the free surface.

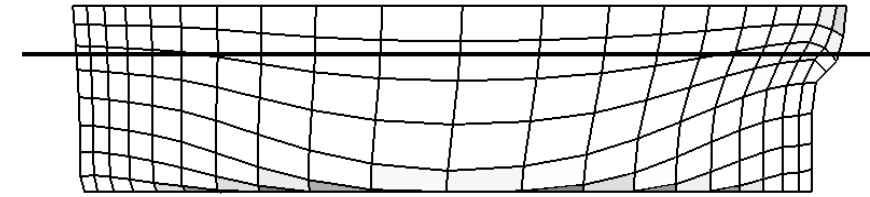

$(5-1)$

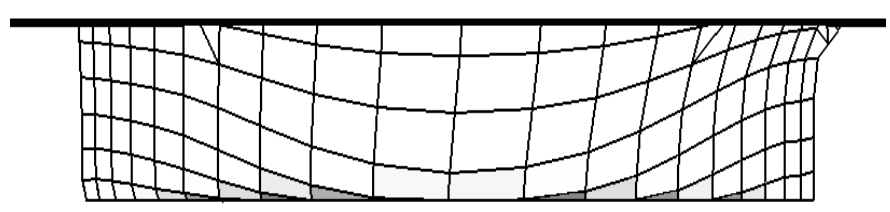

$(5-2)$

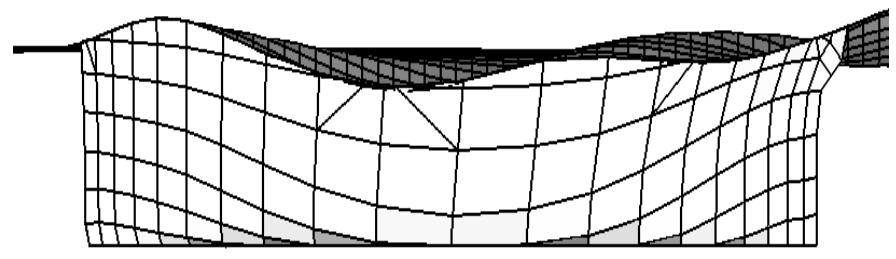

$(5-3)$

Fig. 5 Re-generated panels and free surface in each iteration

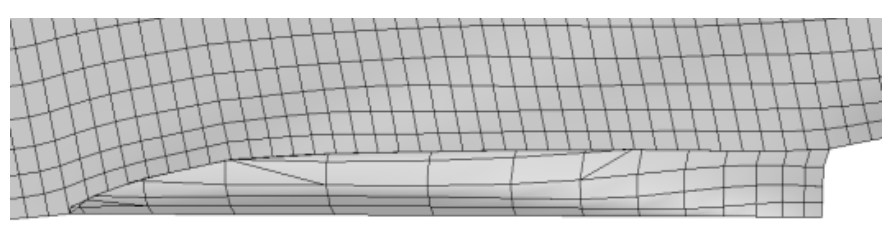

$(6-1)$

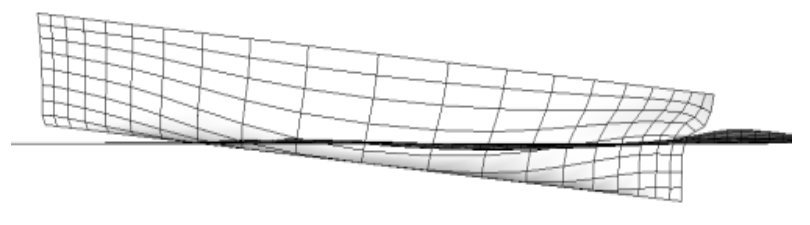

$(6-2)$

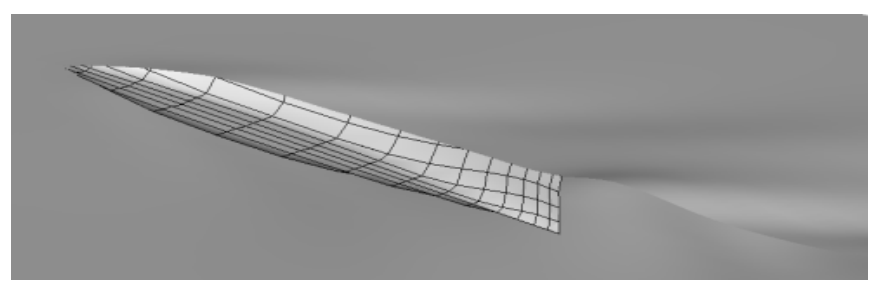

$(6-3)$

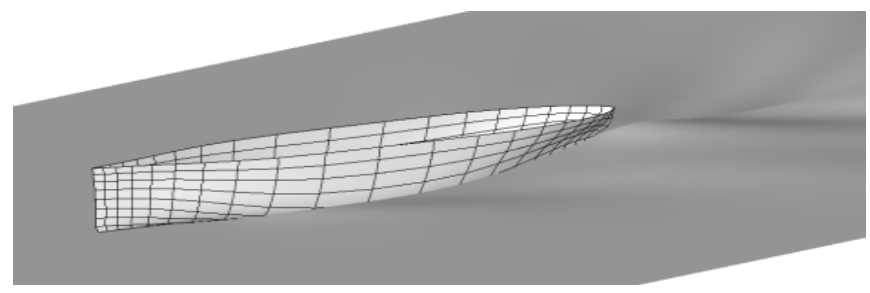

$(6-4)$

Fig. 6 Panels and waves with excessive trim and sinkage. 
The newly generated panel could be too small to perform the numerical computation due to the performance of a computer and a fatal numerical error might occur. To prevent numerical difficulty, the panel less than 1/10 times the minimum panel is eliminated in the present study and the minimum size of the panel should be determined according to the initially given hull panels.

Fig. 5-1 shows the initially given hull panels of Series 60 $\left(C_{B}=0.60\right)$ hull. Figs. 5-2 and 5-3 show the newly generated hull panels according the undisturbed free surface and the wavy free surface.

Fig. 6 shows the panels of a ship and the wave pattern in which the ship experiences the excessive dynamic trim and sinkage. Fig. 6-1 shows the computational panels generated in the final iteration and Fig. 6-2 shows the side view. Figs. 6-3 and 6-4 show the view below and above the free surface, respectively. As shown in Figs. 6-2 and 6-4, the bottom of the bow is above the free surface.

\section{APPLICATIONS}

Numerical computations were performed to investigate the validity of the proposed algorithm. The computational results were validated by comparing them with the existing experimental data.

\section{Series $60\left(C_{B}=0.60\right)$ hull}

For the first example, a well known hull shape, Series 60 $\left(C_{B}=0.60\right)$ hull, was selected. This is a standard ship hull which has been used extensively as a verification reference of the developed numerical analysis code.

As shown in Fig. 7, the ship lies from $-0.5 \mathrm{~L}$ to $0.5 \mathrm{~L}$ and the hull surface panels in the vicinity of the stern and the bow are more densely allocated than the panel assigned amidships.

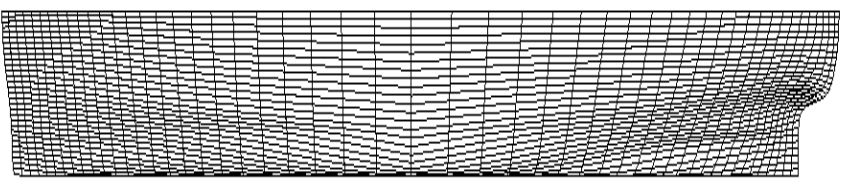

Fig. 7 Hull surface panel distribution for Series $60\left(C_{B}=0.60\right)$ hull.

Fig. 8 shows the panel distribution which defines the free surface. The range of the free surface is $-1 L$ to $1.5 L$ with longitudinal direction and $0.7 \mathrm{~L}$ with transverse direction. The size of the panel with longitudinal direction, $\delta x_{F S}$ is identical but with transverse direction, $\delta y_{F S}$ it was more densely distributed in the vicinity of the ship since the change of the flow is more serious. The collocation point, $x$ in which the free surface boundary condition should be satisfied was shifted upstream from the centroid of the quadrilateral panel to ensure a more stable convergence of the solution.
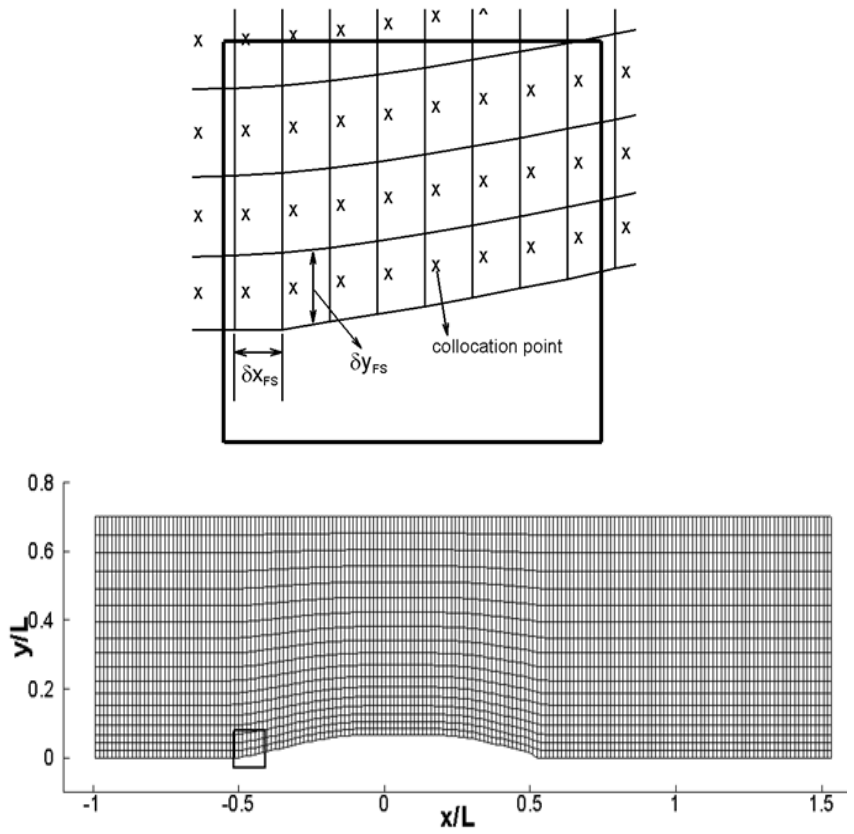

Fig. 8 Free surface panel distribution.

In Fig. 9, the non-dimensional wave contour computed at the speed of $F n=0.316$ is compared with the measured data and since precise comparisons are fairly difficult to make, the general appearance is correct. Fig. 10 compares the longitudinal wave cuts at $y / L=0.08,0.10,0.15$ and the bow wave system is well predicted but the stern wave system is significantly overestimated. This may, at least partly, be due to viscous effect.
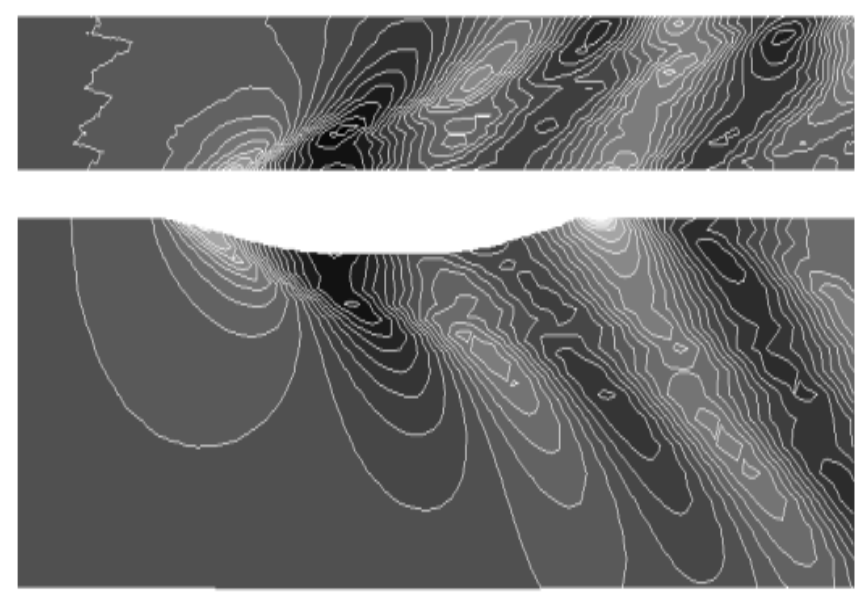

Fig. 9 Comparison of wave pattern at $F n=0.316$ for Series 60 $\left(C_{B}=0.60\right)$ hull (Upper=Experiment, Lower=Computation).

Fig. 11 compares the computed wave resistance coefficient with the experimental. The computed wave resistance coefficients are those found by integration of the pressure coefficient over the part of the hull under the wavy waterline. The computed wave resistance coefficient predicts well the experimental data over the entire speed range. 


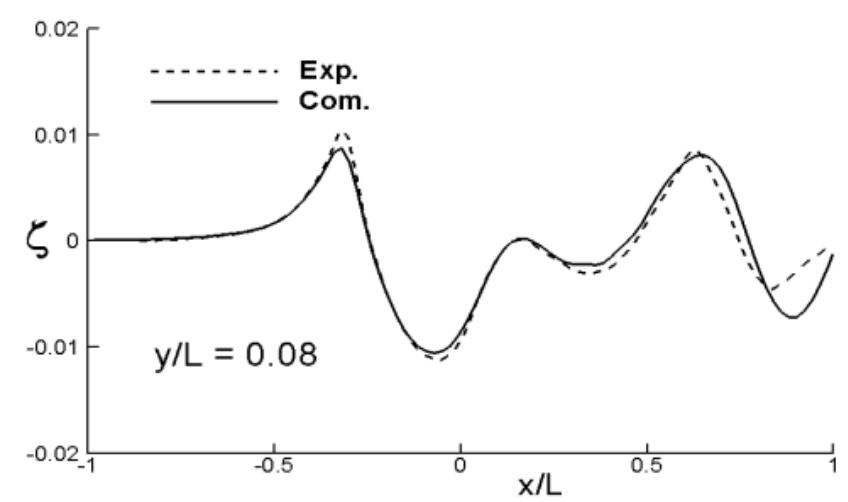

\section{KCS}

For the second example, KCS was selected as the object ship. The principal particulars are described in Table 1. The service speed of the ship is $2.196 \mathrm{~m} / \mathrm{s}(F n=0.26)$. The ship has a bulbous bow and a transom stern as shown in Fig. 12 and special treatment should be imposed in the first points aft of the transom stern to satisfy the free surface condition (Raven, 1996).

Table 1 Principal particulars of KCS.

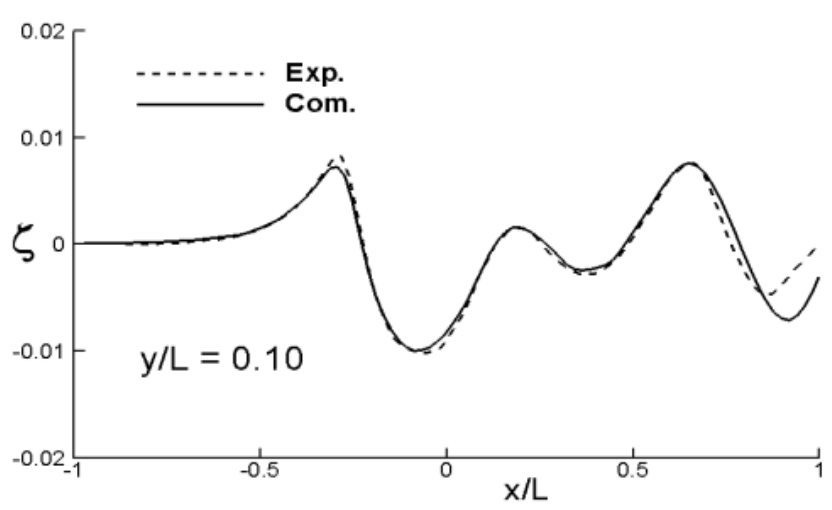

\begin{tabular}{|lr|l|}
\hline Length between perpendicular & $L B P(m)$ & 7.2786 \\
\hline Breadth, moulded & $B(m)$ & 1.0190 \\
\hline Draft, moulded & $T(m)$ & 0.3418 \\
\hline Wetted surface Area & $S\left(\mathrm{~m}^{2}\right)$ & 9.5121 \\
\hline Displacement volume & $\left(\mathrm{m}^{3}\right)$ & 1.6490 \\
\hline
\end{tabular}

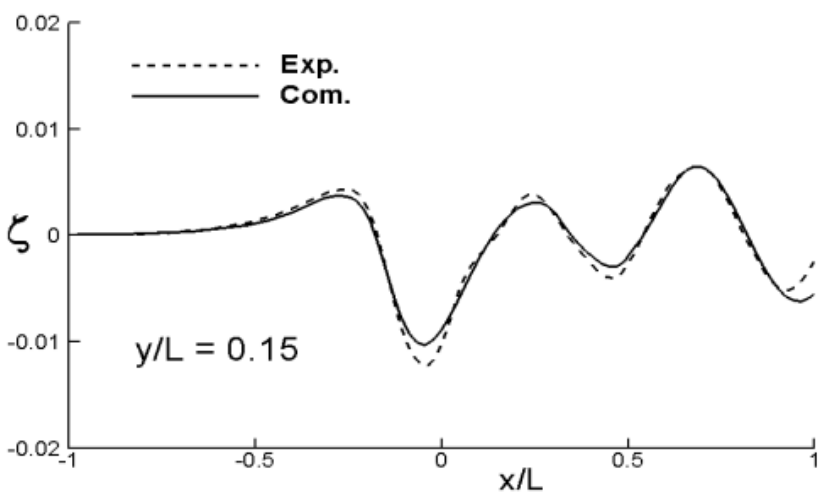

Fig. 10 Comparison of longitudinal wave cuts for Series 60 $\left(C_{B}=0.60\right)$ hull.

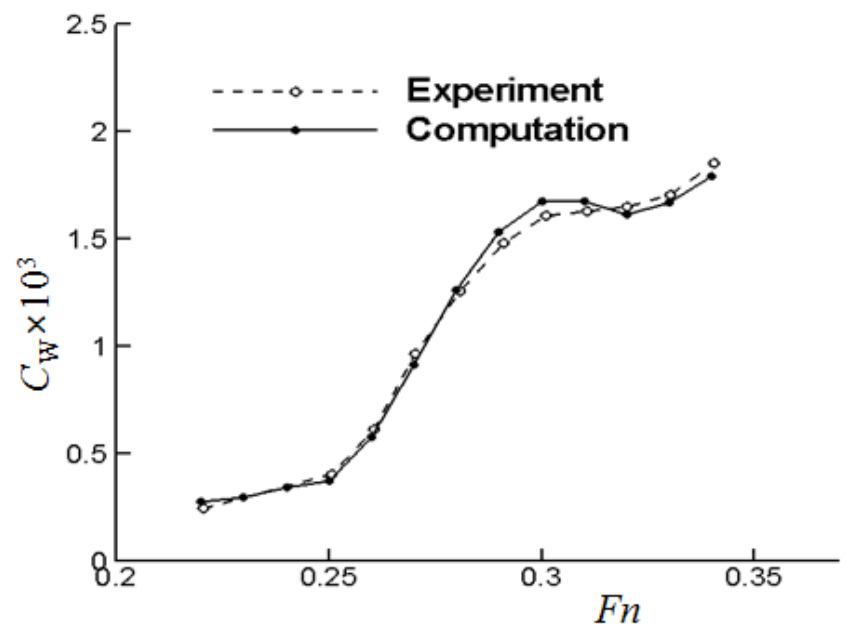

Fig. 11 Comparison of $C_{\mathrm{w}}$ for Series $60\left(C_{B}=0.60\right)$ hull.

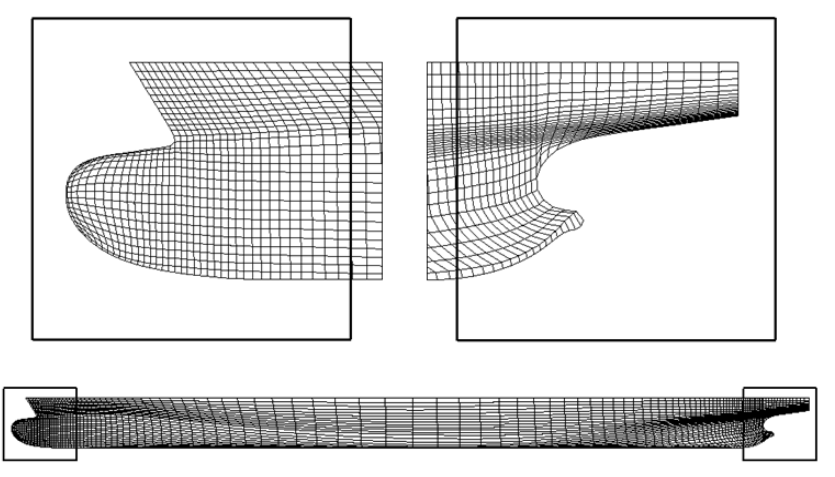

Fig. 12 Hull surface panel distribution for KCS.

In Fig. 13, the non-dimensional wave contour computed at the service speed is compared with the measured data and the general appearance is correct. Fig. 14 compares the longitudinal wave cuts at $y / L=0.08,0.10,0.15$ and the bow wave system is well predicted, but the stern wave system is significantly overestimated, as in Series $60\left(C_{B}=0.60\right)$ hull.

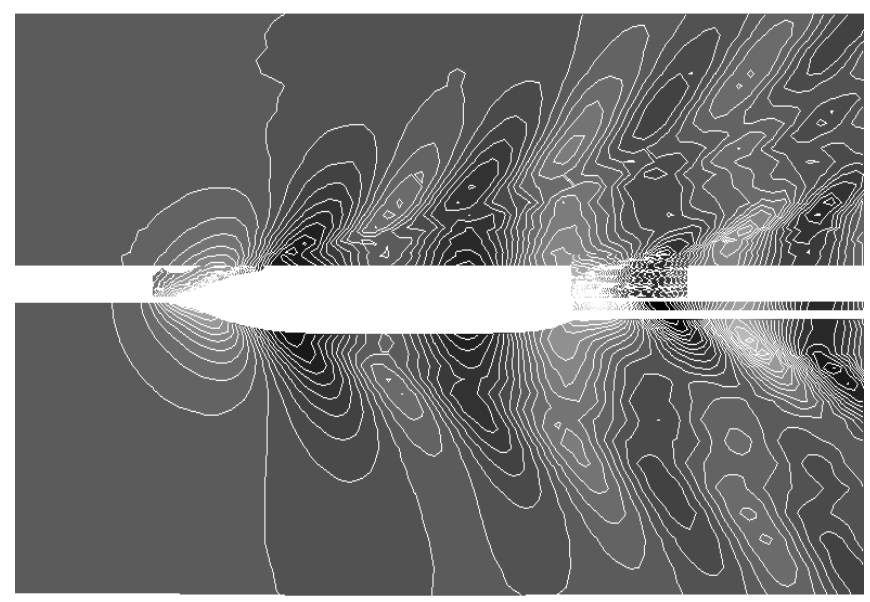

Fig. 13 Comparison of wave patterns at $F n=0.26$ for KCS (Upper=Experiment, Lower=Computation). 

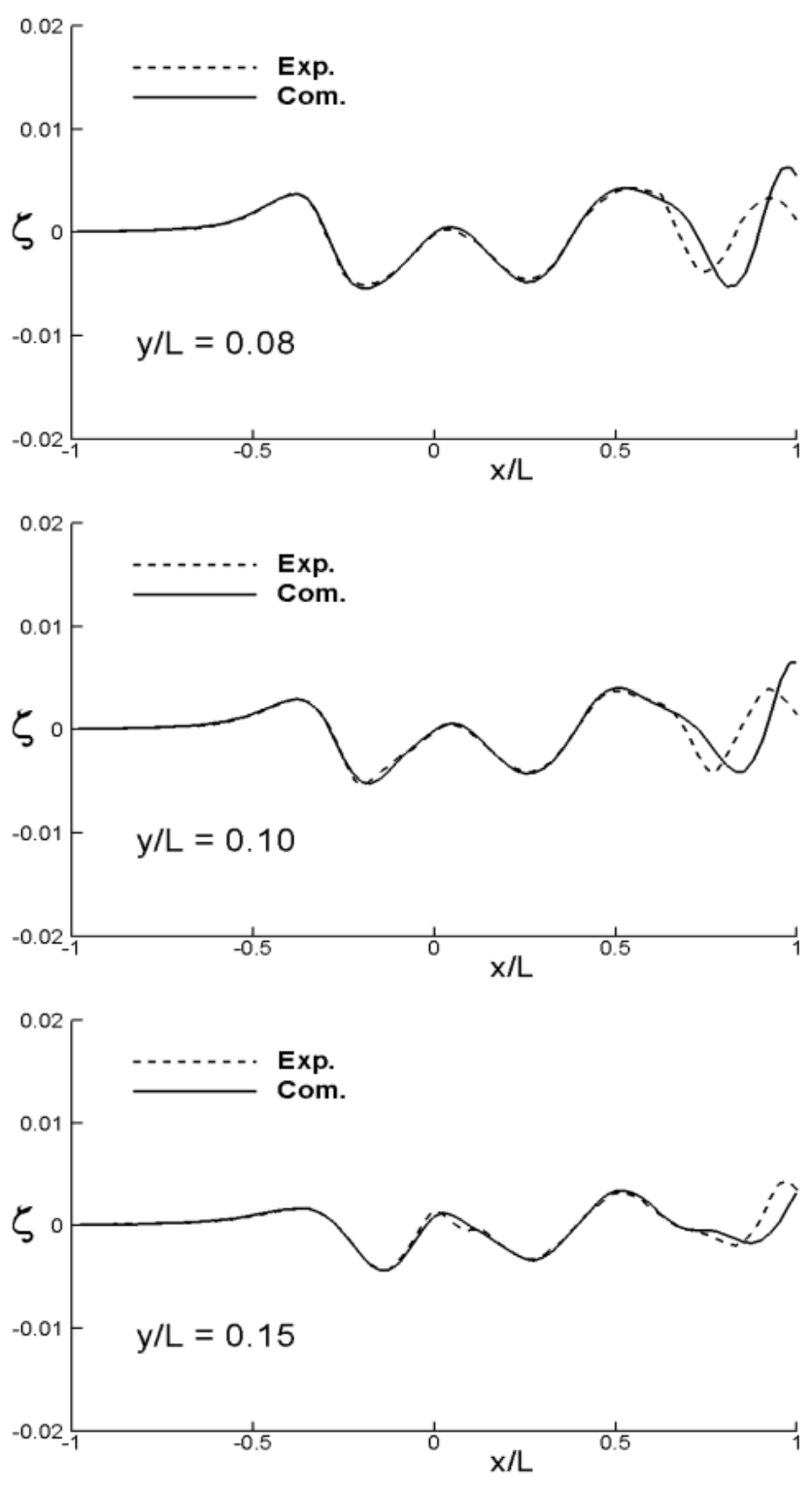

Fig. 14 Comparison of longitudinal wave cuts for KCS.

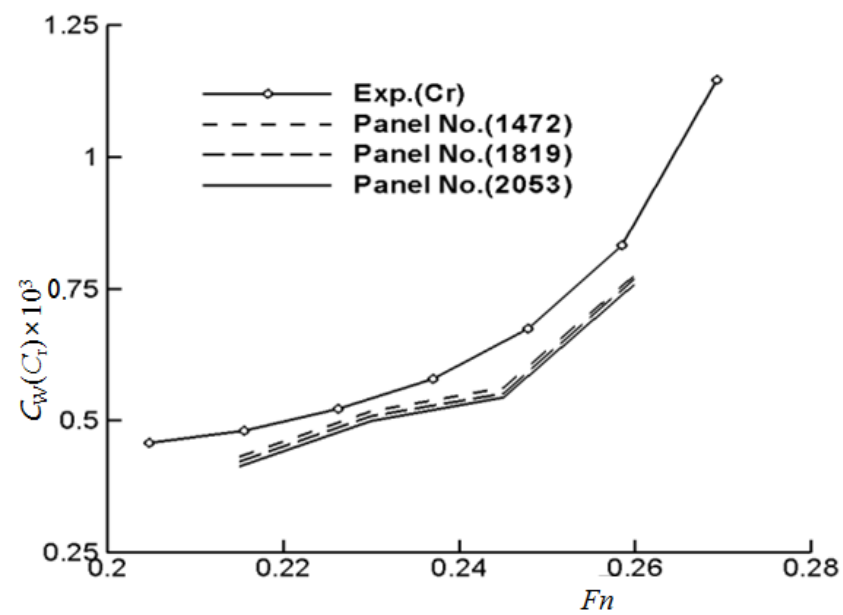

Fig. 15 Convergency test for the hull panel number for KCS.
Fig. 15 shows the comparison of the computed wave resistance among the 3 different hull panel numbers. The numbers $(1472,1819,2053)$ in the blank represent the panel numbers. The computed wave resistance is converged to the finer hull panel and the wave resistance of the finer hull panels is lower than the coarse panels.

Fig. 16 compares the computed wave resistance coefficient with the experimental residual resistance coefficients. The computed wave resistance coefficient is slightly lower than the experimental residual resistance coefficients since the viscous form drag is included in the residual resistance coefficients.

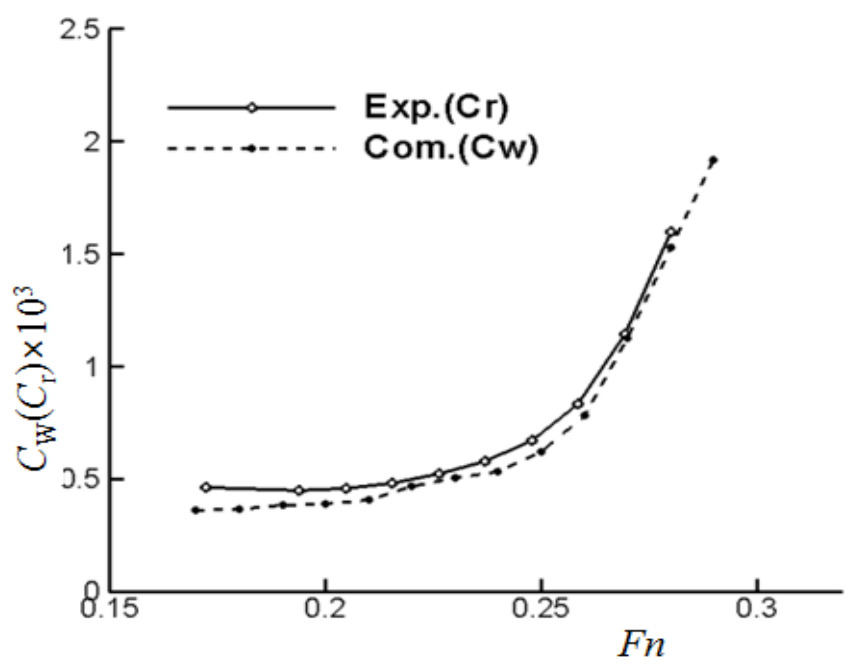

Fig. 16 Comparison of $C_{\mathrm{w}}\left(C_{\mathrm{r}}\right)$ for KCS.

\section{CONCLUSIONS}

In the present study, a new hull panel generation technique was proposed in which the panel on the hull was re-generated, making the best use of the initially given panels. The Rankine source panel method was used with the fully nonlinear free surface condition, which was satisfied by the iterative method and the dynamic trim and sinkage were taken into account.

The computational results were compared with the experimental data. The performance of the panel cutting method was proven to be commendable and the method might be applicable for a ship with complicated geometry and excessive dynamic trim and sinkage. More study for several types of ships is recommended in future work.

\section{ACKNOWLEDGEMENTS}

This work was supported by the National Research Foundation of Korea (NRF) grant funded by the Korea government (MEST) through GCRC-SOP (Grant No. 20110030658). 


\section{REFERENCES}

Baba, E. and Takekuma, K., 1975. A study on free-surface flow around bow of slowly moving full forms. Journal of Society of Naval Architects of Japan, 137, pp. 1-10.

Brandsma, F.J. and Hermans, A.J., 1985. A quasi-linear free surface condition in slow ship theory. Schiffstechnik, Bd. 32.

Bronsart, R. and Knieling, G., 2004. Automatic Generation of a Panel based Representation of a Ship Hull Surface for Wave Resistance Calculation. 9th International Symposium on Practical Design of Ships and other Floating Structures (PRADS), Lübeck.

Dawson, C.W., 1977. A practical computer method for solving ship-wave problems. 2nd International Conference, Numerical Ship Hydrodynamics, Berkeley, pp. 30-38.

Eggers, K.W.H., 1981. Non-Kelvin dispersive waves around non-slender ships. Schiffstechnik, Bd. 28.

Gadd, G.E., 1976. A method of computing the flow and surface wave pattern around full forms. Trans. RINA, 118 , pp. 207-219.
Jensen, P.S., 1990. Automatic Panel Generation for Seakeeping and Wave Resistance Calculation. CFD and CAD in ship Design, Elsevier, pp. 133-146.

Kim, W.J. and Van, S.H., 1999. Practical method for generating surface mesh using offset table. Journal of the Society of Naval Architects of Korea, 36(1), pp. 6169.

Ko, K.H. Park, T.Z. Kim, K.H. Kim, Y.H. and Yoon, D.H., 2011. Development of panel generation system for seakeeping analysis. Computer-Aided Design, 43(8), pp. 848-862.

Kouh, J.S. and Chau, S.W., 1993. Computer-aided geometric design and panel generation for hull forms based on rational cubic Bezier curves. Computer Aided Geometric Design, 10, pp. 537-549.

Newman, J.N., 1976. Linearized wave resistance theory. International Seminar on Wave Resistance, Tokyo, Japan, pp. 31-43.

Raven, H.C., 1996. A solution method for the nonlinear ship wave resistance problem. Ph.D. Thesis, Delft University, Netherlands. 